\title{
Long-run Effects of Real-time Electricity Pricing in the Saudi Power Sector
}

Walid Matar 


\section{About KAPSARC}

The King Abdullah Petroleum Studies and Research Center (KAPSARC) is a non-profit global institution dedicated to independent research into energy economics, policy, technology and the environment across all types of energy. KAPSARC's mandate is to advance the understanding of energy challenges and opportunities facing the world today and tomorrow, through unbiased, independent, and high-caliber research for the benefit of society. KAPSARC is located in Riyadh, Saudi Arabia.

This publication is also available in Arabic.

\section{Legal Notice}

(c) Copyright 2021 King Abdullah Petroleum Studies and Research Center ("KAPSARC"). This Document (and any information, data or materials contained therein) (the "Document") shall not be used without the proper attribution to KAPSARC. The Document shall not be reproduced, in whole or in part, without the written permission of KAPSARC. KAPSARC makes no warranty, representation or undertaking whether expressed or implied, nor does it assume any legal liability, whether direct or indirect, or responsibility for the accuracy, completeness, or usefulness of any information that is contained in the Document. Nothing in the Document constitutes or shall be implied to constitute advice, recommendation or option. The views and opinions expressed in this publication are those of the authors and do not necessarily reflect the official views or position of KAPSARC. 


\section{Key Points}

his study estimates the effects of real-time electricity pricing (RTP) on long-run marginal power generation costs in Saudi Arabia. For this purpose, this study links a multi-sector energy system model with a residential electricity use model. The energy system model includes an economic power dispatch optimization component. The residential framework embeds households, whose decisions are governed by microeconomic principles, within a physical building energy model. The analysis entails liberalizing fuel prices for power utilities and setting dynamic electricity prices equal to the long-run marginal cost of supplying electricity. The electricity prices are offered solely to households. The key takeaways from this analysis are as follows:

RTP, a form of dynamic electricity pricing, reduces the intraday variability of Saudi power utilities' marginal costs.

RTP results in lower power loads, and consequently drives reduced capital spending by the Saudi power sector. The resulting curtailed investments in power plants more than cover the cost of residential smart meter replacements. 


\section{Summary}

$\mathrm{T}$ his study explores the potential effects of real-time electricity pricing on the operations

of Saudi Arabia's power generation sector.

The Kingdom currently sets fuel prices for power utilities at levels that suppress the costs of power generation. However, this analysis provides insights into the effects of a real-time electricity pricing scheme in the context of liberalized fuel prices.

To this end, the analysis combines two modeling frameworks. The first is the KAPSARC Energy Model, a multi-sector energy system model for Saudi Arabia. The second is a model of residential electricity use. This residential model embeds households, whose decisions are governed by welfare maximization, within a physical building energy model. The models are run iteratively to determine long-run equilibrium marginal power supply costs and residential load curves. The term 'long-run' is time agnostic. It refers to a time in the distant future when a steady state is reached given the data for some base year.

The analysis entails dividing households into low- and high-income groups living in various archetypical dwelling types. The analysis also accounts for the specific socioeconomic and climate characteristics of different regions within the country. Along with assuming liberalized fuel prices, the analysis specifies real-time pricing (RTP) as the time-varying long-run marginal cost of supplying electricity. RTP is offered solely to households, and the electricity prices charged to other consumer segments remain unchanged. This analysis applies RTP to all households because the study aims to examine RTP's effects on the power system at large.
The analysis leads to two key takeaways. First, RTP reduces the variability of the marginal costs to Saudi power utilities throughout the day relative to the scenario with no RTP. When fuel prices are liberalized, the prices under RTP are higher than 2017 electricity prices. Hence, the power loads are lower, leading to lower investments in power plants in the long run. The growth in solar photovoltaic (PV) capacity in the Saudi power system is also lower. Without energy storage, lower additional PV capacity mitigates the wide variation in the marginal cost of production between day and night.

Second, the curtailed investments in power plants expected as a result of RTP can more than cover the costs of residential smart meter replacements. Total investments over time are estimated to be about $\$ 24$ billion lower in the scenario with RTP. By comparison, the actual cost of smart meter replacements for all residential customers is $\$ 2.4$ billion. 


\section{Introduction}

audi Arabia recently began replacing residential customers' conventional analogue electricity use meters with digital meters. Argaam (2019) reports that the total cost of this replacement is 9 billion Saudi riyals (SAR). The Saudi Electricity Company (SEC) is entirely covering this cost. Once this change is complete, the SEC will be able to simplify its billing operations and access time-of-use (ToU) power load information. Relevant to the scope of this study, the SEC will also be able to charge time-varying electricity rates. As Yang, Meng and Zhou (2018) discuss, dynamic prices are one category of the price-based demand response tools that power utilities may exercise.

Dutta and Mitra (2017) classify static and dynamic electricity pricing into the broad categories shown in Table 1. Of these options, local electricity regulators may prefer a ToU electricity pricing scheme as a first foray into dynamic pricing. Matar (2017, 2018, 2019, 2020) has previously analyzed hypothetical ToU tariffs for residential customers in the Saudi context. Because Saudi Arabia has no previous experience with dynamic prices, however, those analyses are not empirical in nature. As an extension of past studies of ToU prices, this study aims to discuss the effects of real-time electricity pricing on Saudi power suppliers. In particular, this study focuses on suppliers' marginal power generation costs, which depend on their fuel use and power capacity investments. Under real-time pricing (RTP), prices vary throughout the day based on the marginal cost of supplying electricity.

To understand the effects of RTP, this study uses the KAPSARC Energy Model (KEM) and a residential electricity use framework. The core version of $\mathrm{KEM}$ is an equilibrium model consisting of six energy or energy-intensive sectors in the Saudi economy (KAPSARC 2016). Electric power generation is one of those six sectors. The model also divides Saudi Arabia into four regions. KEM is temporally aggregated such that each day modeled by it contains eight load segments for power generation. Thus, the model produces eight different marginal costs of electricity per day per region. A single marginal cost therefore reflects the average price over a few hours in a given day.

Table 1. Electricity pricing schemes, based on Dutta and Mitra (2017).

\begin{tabular}{l|l}
\multicolumn{1}{c|}{ Pricing scheme } & \multicolumn{1}{c}{ Brief description } \\
\hline Flat tariffs & A single electricity price over time. \\
\hline Tiered tariffs & $\begin{array}{l}\text { Prices that scale with the quantity of electricity used in each billing period, with } \\
\text { different quantity tiers applied regionally. }\end{array}$ \\
\hline Seasonal tariffs & Static electricity prices in each seasonal period. \\
\hline Time-of-use (ToU) tariffs & $\begin{array}{l}\text { Fixed time-varying rates that are chosen to incentivize customers to shift their } \\
\text { loads to certain times of day. }\end{array}$ \\
\hline Critical peak pricing & A dynamic electricity price that is highest during the peak load segment. \\
\hline Real-time pricing (RTP) & $\begin{array}{l}\text { A dynamic electricity price that reflects the marginal cost of supply instantaneously, } \\
\text { where instantaneity can be defined on various time scales. }\end{array}$ \\
\hline Peak-time rebates & Rebates provided to customers for electricity use below a pre-determined quantity.
\end{tabular}


The residential electricity use paradigm, which is linked to the electric power sector, merges microeconomic concepts with a conventional building energy model (Matar 2020). This model ultimately produces power load curves for the residential sector. The load curves are a product of households' behavioral adjustments or energy efficiency purchases as they aim to maximize welfare. Through this linkage, this study investigates the long-run marginal costs of power generation and delivery ${ }^{1}$ at the fuel prices offered to power plants at 2017 market prices.
The remainder of this paper proceeds as follows. The next section describes time-varying electricity pricing. It also provides an in-depth look at past studies of dynamic electricity prices and the additional insights that may be obtained from this study. The following section lays out this study's methods and energy pricing scenarios. The results are presented next, followed by a summary of the findings in the conclusion. 


\section{Time-varying Electricity Pricing}

$\mathrm{n}$ economic theory, a good's pricing is deemed to be efficient when its marginal cost of supply is equal to its marginal value of demand (Dewees 2001). Generally, electricity generators' short-run marginal costs are used to instantaneously decide which generator should satisfy the demanded power load. If the electricity price is fixed, this constant response process is the power suppliers' responsibility. Conversely, wholesale and retail electricity markets attempt to ensure economic efficiency by adjusting the quantities supplied and demanded based on an equilibrium price. This equilibrium price is discovered concurrently to the quantity adjustments. In this case, the highest marginal cost of generation equals the highest marginal value of demand. The electricity market undergoes this process continuously throughout the day. The electric power load varies over time, and widespread electricity storage is lacking. Thus, the short-run marginal costs, and, in turn, the equilibrium prices, vary over time as well. In practice, however, most regions do not have a market in which suppliers and consumers can quickly respond to changing loads or prices throughout the day.

Even in regulated settings, electricity may be priced to reflect the costs of electricity generation, transmission and distribution. Regulated prices may reflect the costs for all consumers. However, they may be set such that they do not reflect the true costs for a particular customer group. In the Gulf Cooperation Council (GCC), for example, electricity prices have remained time-invariant and cross-subsidized between consumer segments. For instance, households and schools in GCC countries pay below-cost rates, whereas other consumer segments, particularly the government, pay above-cost rates. The Electricity and Co-Generation Regulatory Authority (ECRA) (2018) reports that the average electricity cost of service ${ }^{2}$ in Saudi Arabia was $\$ 0.0544$ per kilowatthour (kWh) in 2017. The same report states that in 2017, the government's electricity tariff was fixed at $\$ 0.0853$ per $\mathrm{kWh}$, and the industrial tariff was $\$ 0.0480$ per kWh. By comparison, the residential tariff started at $\$ 0.0133$ per kWh for the first 2 megawatthours (MWh) of use per month.

Various studies have shown that moving to dynamic prices can achieve higher economic efficiency. For instance, Faruqui, Hledik and Palmer (2012) discuss the tradeoffs between the risks and rewards of time-varying pricing schemes from the consumer's perspective. They define a pricing scheme's reward as the potential to save money and its risk as exposure to potential price volatility. Their illustration starts with a flat tariff scheme and culminates with RTP. They find that increasing the variability of electricity prices over time generally increases the reward but also the risk. This relationship is envisaged as being non-linear, as the risk increases more rapidly than the reward does as prices approach RTP.

Faruqui and Sergici (2010) report that in the 2000s, regulators in the United States investigated if and to what extent customers' electricity demand responded to dynamic electricity prices. To this end, 15 nationwide experiments of ToU and critical peak pricing were surveyed. Their results varied highly depending on the extent of the price increase and consumers' access to enabling technologies to substitute or shift their electricity use.

Allcott (2011) studies the effects of the first experimental program in the United States to test hourly RTP for households. He finds that households responded in the short run by conserving energy or making behavioral adjustments during peak hours. However, they did not shift their electricity use to off-peak hours. 
Around that time, Faruqui, Sergici and Akaba (2013) studied the price responses of residential customers in Michigan to peak-time rebates and critical peak pricing. These electricity pricing schemes differ from RTP but are also forms of dynamic pricing. The authors utilize constant elasticity of substitution functions to estimate customers' aggregate price elasticities. Specifically, they estimate the extent to which customers responded by shifting loads from peak to off-peak times, as well as daily own-price elasticities. They find a substitution elasticity of -0.11 and a daily elasticity of 0.00 in both pricing cases.

Moreover, Herter, Wood and Blozis (2013) conduct an experimental study of households in California. They show that households that signed up for a time-varying electricity rate rather than the standard tiered electricity price helped the power utilities save between $20 \%$ to $50 \%$ on their peak loads. Those households also reduced their electricity bills in the summer.
All of these studies only provide results for selected regions at a given point in time. Moreover, much of the literature on time-varying electricity pricing analyzes it from the consumer's perspective (e.g., Allcott 2011; Faruqui, Hledik and Palmer 2012; Faruqui, Sergici and Akaba 2013; Herter, Wood and Blozis 2013). Previous research has focused on conducting experimental studies and surveys of residential customers. These past surveys or experiments on dynamic electricity pricing programs confirm the theoretical prediction that power loads fall when consumers face higher prices. This confirmation of the theory goes hand in hand with this study's method, as discussed in the next section. 


\section{Method}

This study links two models:

$\mathrm{KEM}$, an energy system equilibrium model developed for Saudi Arabia.

A residential electricity use model in which a household is embedded in a physical building energy model. The data are calibrated based on household surveys conducted by the Saudi General Authority for Statistics (GaStat). The detailed data inputs come from Matar (2020).

The analysis proceeds as follows. The residential electricity use model outputs power load curve information based on its calculated behavioral adjustments and energy efficiency purchases. The outputted residential power load curve is added to those of the other consumer segments. The energy system model outputs the operational decisions that the power system makes to meet the inputted load demand. The linkage entails iterating between the two models until both the load curves and electricity prices converge. The electricity prices used in this analysis are the marginal costs of power generation and transmission. This pricing scheme is henceforth referred to as RTP.

Both models define four regions of Saudi Arabia, as illustrated in Figure 1. The regions are based on the SEC's operating areas and have varying socioeconomic and climatic attributes.

Figure 1. The four Saudi regions, as represented and defined in KEM and the residential electricity model.

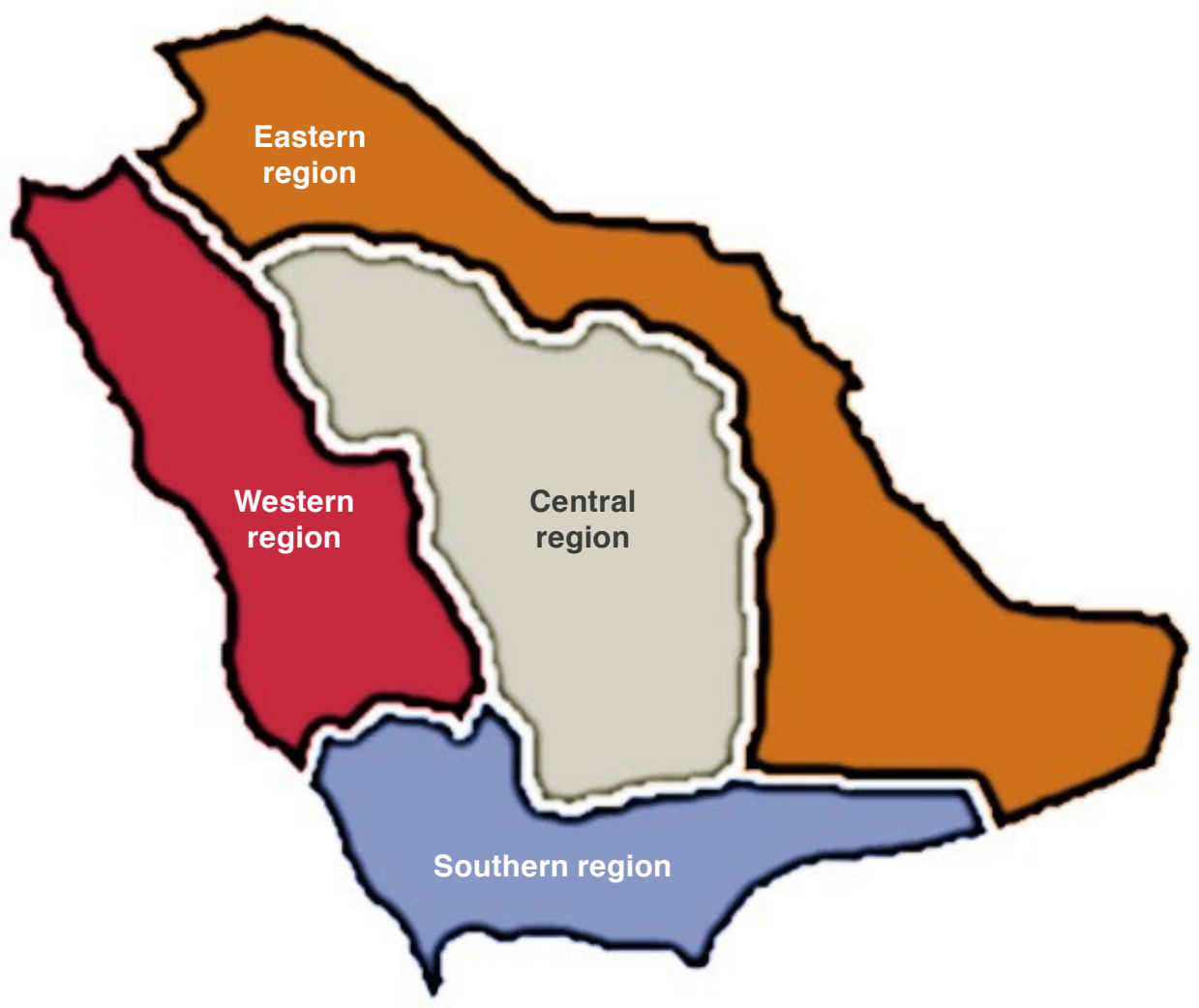

Source: KAPSARC (2016). 


\section{The KAPSARC Energy Model}

KEM is a multi-sector energy system model for Saudi Arabia (KAPSARC 2016). As Figure 2 shows, it consists of six energy or energy-intensive sectors. These sectors are electricity, cement production, petrochemicals and fertilizers, water desalination for municipal water use, oil and natural gas extraction and transportation, and oil refining. The model characterizes each sector's operational and investment decisions. Each sector aims to either minimize costs or maximize profits. The power generation sector is formulated as minimizing costs to meet the power load demand. The model disaggregates Saudi Arabia into four regions that are consistent with the SEC's operating areas. KEM's data inputs for 2015 are detailed by Matar and Anwer (2017) and Matar and Shabaneh (2020). Those data are used for this analysis.
The power generation sector covers all existing technologies in the Saudi power system. It also incorporates prospective technologies that Saudi Arabia may deploy, such as nuclear and solar thermal power, for potential investment. To keep the model size tractable, it makes operational decisions for representative weekdays and weekends in the summer, winter and an intermediate seasonal period for each region. Furthermore, it discretizes each representative day into eight load segments. The model outputs the long-run marginal costs for each load segment. Thus, a single marginal cost output by the model is an average of the costs over a few hours in a given day.

The households' chronological power load curves, which are inputs to KEM, are determined by the residential electricity use model. These power loads inform the total load demand, which the power generation sector has to meet. Based on

Figure 2. KEM.

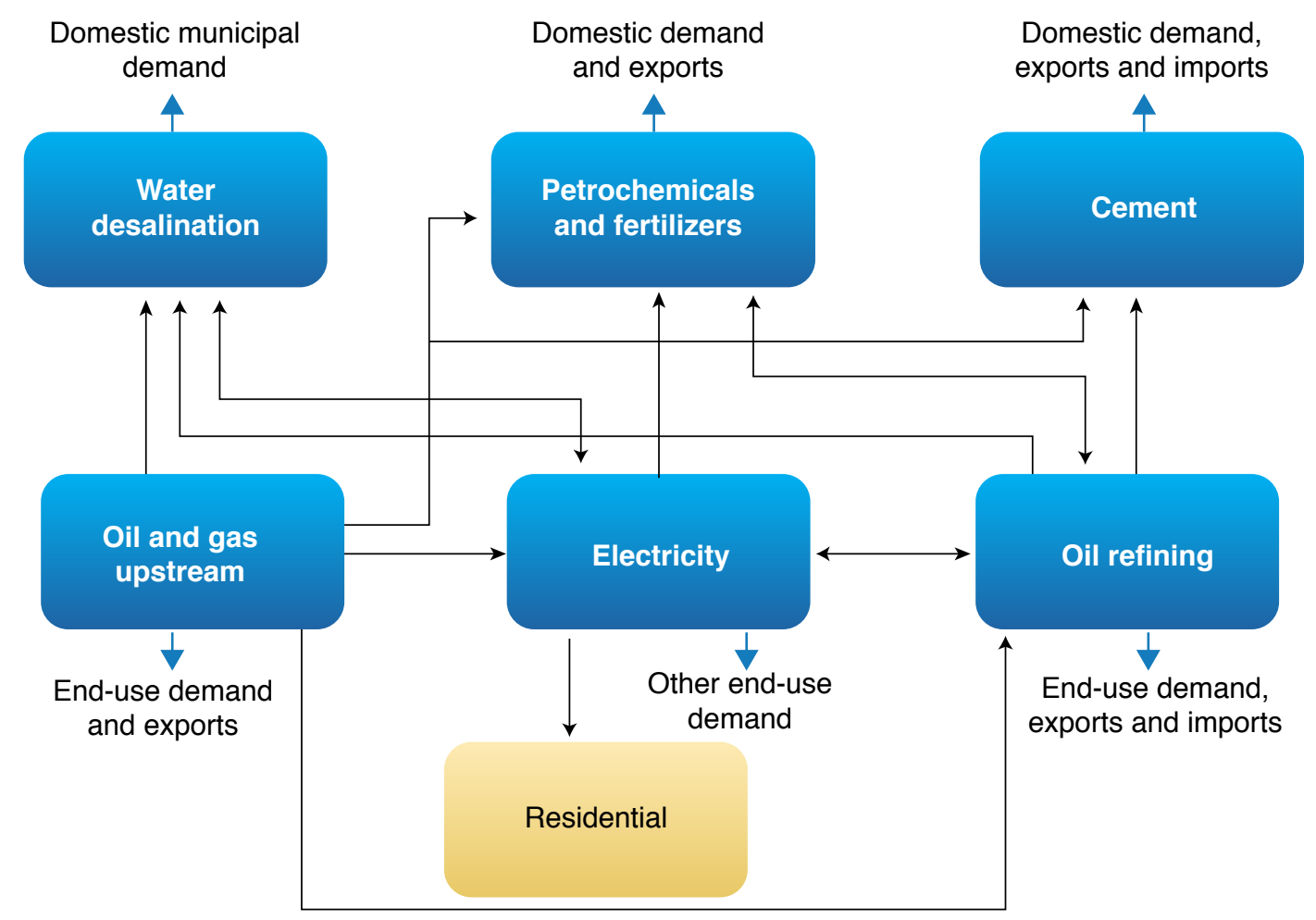

Source: KAPSARC (2016). 
this information, the sector makes appropriate long-run operational and plant investment decisions. 'Long-run' is defined as the steady state that occurs at some point in the future. The operational decisions include the levels of chronological fuel use, which change as households respond to changing electricity prices by altering their loads. Other sectors, such as the oil refining industry, may subsequently change their operations as well.

\section{Residential electricity use model}

At a high level, Figure 2 shows the link between the residential electricity use model and the power generation sector in KEM. The residential model is described by Matar $(2018,2019,2020)$. The residential component merges the microeconomic fundamentals that economists use to study household decision-making with the physical laws that govern a dwelling's energy flows. Figure 3 illustrates the basic structure of the framework, and Matar (2020) provides a more detailed description of the data calibration and inputs.

In the microeconomic component of the model, households' decisions are guided by a utility function that measures their welfare or satisfaction (Johansson 1991). The electricity consumption variables in this utility function are defined by the physical building energy model. The physical component $^{3}$ of the model characterizes the conductive, radiative and convective forms of heat that are transferred into and out of the air inside a thermal envelope. In that respect, the model resembles commercial building energy models. Unlike those models, however, this model was designed from the bottom up to be linked with KEM. It is intended to facilitate further development for the purposes of energy economics research. It incorporates the sensible and latent heat gains or losses as a result of air exchanges. These exchanges may be between indoor and outdoor air, windows, lighting, and internal elements, such as occupancy and appliances. The total hourly power load is the sum of three components. These components are direct use by light bulbs and appliances, the power required to run the supply and return fans of the air-handling units, and the power drawn from the air conditioners' refrigeration cycle. The refrigeration cycle's power usage is directly related to the amount of heat transferred into and out of the interior to achieve the desired indoor temperature and relative humidity level. The physical component is designed in this way to enable the analysis of specific energy efficiency measures.

The levels of energy use that are determined by the physical component of the model are fed to the microeconomic component. The microeconomic component uses a constant elasticity of substitution utility function, as shown by the top-most formulation in Figure 3. Although the elasticity of substitution is fixed, the own-price elasticity of the demand for goods can vary based on shares of expenditures. $x_{i}$ represents electricity use by service in MWh. $\phi_{i}$ is an adjustment factor that estimates the utility gained from installing energy efficiency measures. In other words, $\phi_{i}$ adjusts for any reduction in electricity use due to energy efficiency by modifying $x_{i} \phi_{i}$. Matar (2020) provides a more detailed description of $\phi_{i}$. The consumption of other goods and services is determined in monetary terms, with the price of other goods and services being set to unity.

$\alpha_{i}$ represents households' preferences, which sum to unity for all $i$. The households are calibrated such that their preference shares for electricity range from $0.5 \%$ to $35 \%$. A household's preference share depends on its region and income, as will be explained later. This calibration is performed by setting electricity preferences near zero and 
Figure 3. The residential physical-microeconomic framework.

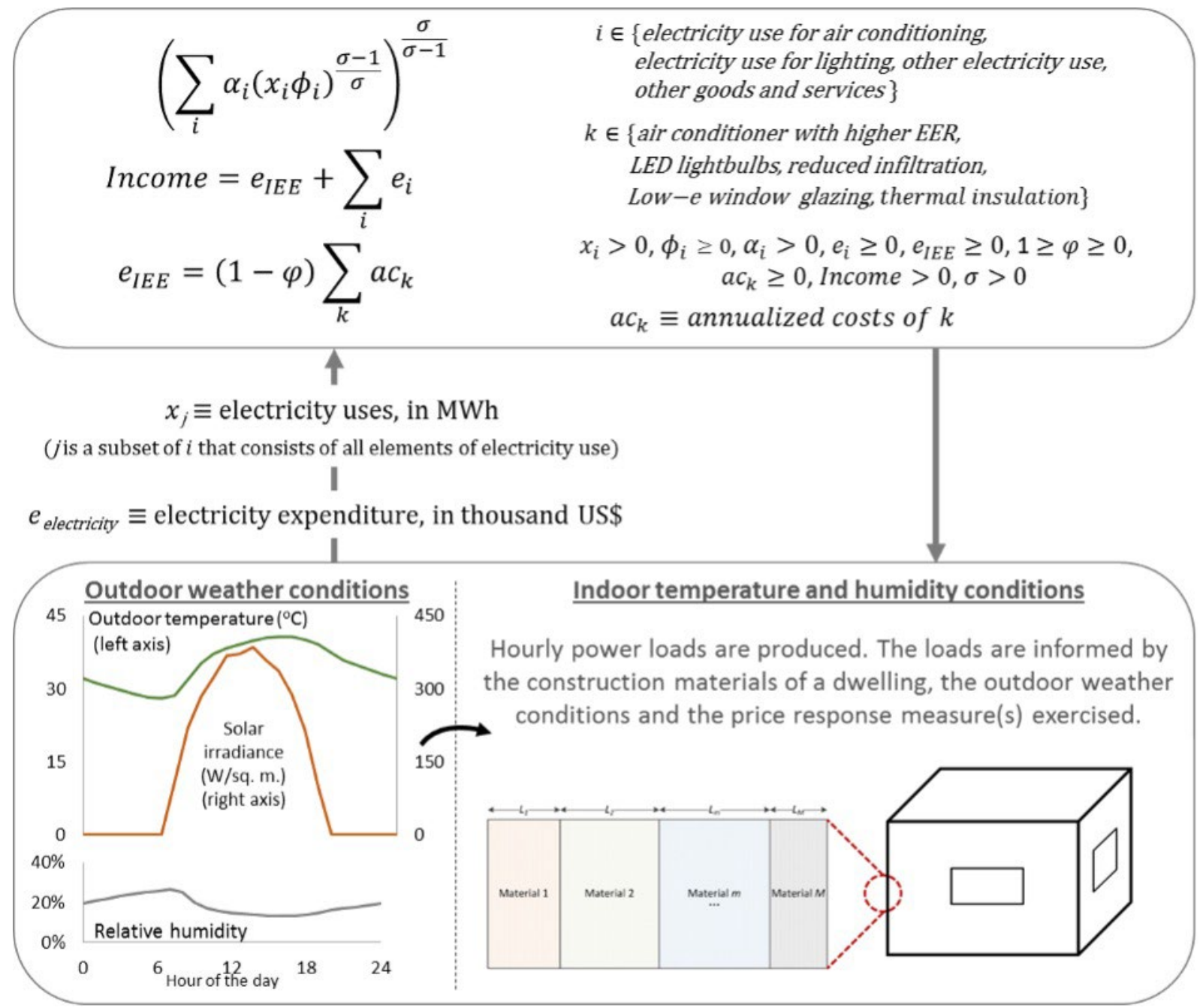

Source: Matar (2020).

Note: EER = energy efficiency rating; W/sq.m. = Watts per square meter.

slowly raising them until the households no longer respond behaviorally to the 2017 electricity tariffs. The preference share devoted to electricity is further disaggregated into its various components. The analysis uses estimates based on the 2011 consumption shares for a Saudi household reported by Faruqui et al. (2011). These metrics are shown in Table 2. The preference share of other goods and services is the difference between $100 \%$ and the electricity preference share. Finally, $\sigma$ is the elasticity of substitution, and its calibrated value is 0.9 .

In the budget constraint, Income is the average annual household income by region. Here, it reflects the average 2017-2018 household income for each region reported by GaStat (2018), as shown in the Appendix. The full set of households is split into two income classifications: low- and high-income households. The income levels associated with 
Table 2. Estimated electricity use breakdown for a Saudi household.

\begin{tabular}{c|c} 
Electricity end use & Share of electricity consumption (\%) \\
\hline Cooling & 70 \\
\hline Lighting & 5 \\
\hline Other & 25
\end{tabular}

Source: Estimated by the author based on Faruqui et al. (2011).

each region are tabulated in the Appendix. $e_{i}$ is annual expenditures on electricity and other goods and services. Expenditures on electricity may be computed based on hourly prices or on Saudi Arabia's current progressive (i.e., tiered) pricing structure.

$e_{I E E}$ is the annualized investment and maintenance cost of a particular energy efficiency measure.

The analysis only includes expenditures on greater energy efficiency measures in the income constraint. The effects of these measures appear in the utility function in the form of lower electricity use. Additionally, $\phi$, which specifies the level of subsidies provided by another firm or the government, is set equal to zero here.
The features and costs of the energy efficiency measures incorporated in this analysis, denoted by $k$, are detailed by Matar (2020). The costs vary by region according to the different climates and typical dwelling characteristics. The costs are annualized using an individual discount rate that is consistent with prior studies. This study follows Hausman (1979), Harrison, Lau and Williams (2002) and Enzler, Diekmann and Meyer (2014), who estimate average individual discount rates of around $30 \%$. In contrast, Alberini, Banfi and Ramseier (2013) estimate discount rates for individuals in the range of $1.5 \%$ to $3 \%$, below those that are typically used by private firms. ${ }^{4}$ 


\section{Fuel and Residential Electricity Pricing in the Analysis}

uel prices in 2020 are set by the government (ECRA 2020a). The oil prices offered to power utilities differ from the corresponding international market prices. Natural gas, which is not traded internationally and, thus, is not affected by external prices, is priced below its marginal cost of production (Matar and Shabaneh 2020). These prices lead to low marginal costs of power generation and do not signal investments in more energy-efficient or renewable technologies. The current average electricity tariff reflects the current low electricity service costs (ECRA 2020a).

Recent analyses investigate the energy system effects of partial or full fuel price liberalization (Matar and Anwer 2017; Matar, Echeverri and Pierru 2016; Matar et al. 2015; Matar et al. 2017; Matar and Shabaneh 2020). Moreover, the government plans to raise fuel prices to better match international benchmarks (Saudi Vision 2030 2017). Thus, this study examines the long-run marginal costs of power generation and delivery when the fuel prices offered to power plants are based on 2017 market prices. In the model, investments in new power capacity are based on these fuel prices. This analysis considers fully liberalized oil prices in examining the effects of real-time electricity prices. However, the Kingdom may instead link its domestic oil price to an international benchmark as part of its energy price reform. Matar and Anwer (2017) show that, in 2015, the energy system would have started replacing oil with alternative generation technologies if the oil price reached $\$ 29$ per barrel. Because the cost of the prevailing solar photovoltaic (PV) technology has fallen significantly since 2015 , that threshold oil price has also decreased.

The reference case examines the residential electricity tariffs that were applied in Saudi Arabia in 2017. These tariffs are chosen because the residential electricity use model is calibrated to 2017 for data availability reasons. The Electricity and Co-generation Regulatory Authority (ECRA) details the 2017 electricity tariffs, which are shown in Table 3 (ECRA 2016). The tariffs were revised in 2016 and did not change again until 2018. Since then, the tariffs have remained unchanged as of the end of 2020.

Table 3. 2017 and 2018 residential electricity tariffs in Saudi Arabia.

Monthly electricity use

Up to $2 \mathrm{MWh} 5$

\begin{tabular}{ll}
\hline More than $2 \mathrm{MWh}$ and up to $4 \mathrm{MWh}$ & 10 \\
\hline More than $4 \mathrm{MWh}$ and up to $6 \mathrm{MWh}$ & 20 \\
\hline
\end{tabular}

More than $6 \mathrm{MWh}$

30

Electricity tariff (halalahs per kWh)

20172018

Sources: ECRA (2016, 2018). 
In the alternative electricity pricing case, RTP is applied to households only. As Table 4 shows, residential electricity use constituted nearly half of Saudi Arabia's total electricity use in 2019.

Real-time prices reflect the long-run marginal costs of power delivery over time. By linking KEM and the residential model, these prices can be calculated as the marginal electricity costs at the supply and demand equilibria. The loads demanded by households are impacted by the electricity prices that they are charged. The two models are iterated several times until they converge to an equilibrium. Hence, the electricity prices in the RTP case are presented in the results section.

Table 4. Electricity use by consumer segment in Saudi Arabia from 2017 to 2019.

\begin{tabular}{cccc} 
Consumer segment & \multicolumn{3}{c}{ Share of electricity use (\%) } \\
\cline { 2 - 4 } Residential & $\mathbf{2 0 1 7}$ & $\mathbf{2 0 1 8}$ & $\mathbf{2 0 1 9}$ \\
\hline Industrial & 50 & 16 & 18 \\
\hline Commercial & 16 & 16 & 16 \\
\hline Governmental & 17 & 15 & 14 \\
\hline Other & 13 & 6 & 6
\end{tabular}

Sources: Saudi Arabian Monetary Authority ${ }^{5}$ (SAMA) (2019); SEC (2020). 


\section{Results and Discussion}

Figure 4 shows the amount of energy contained in each fuel used by the power sector. The figure shows data for two fuel price cases: administered fuel prices and liberalized fuel prices. The administered fuel price case is analyzed only for 2017 electricity prices to highlight the present fuel mix. In the case of liberalized fuel prices, both 2017 electricity prices and RTP are analyzed. In this scenario, the electric power sector utilizes more natural gas and invests in more renewable power capacity relative to the status quo. The current level of oil use becomes excessively costly in the long run. Principally, the difference in the fuel use results for the two price cases is consistent with Matar,
Echeverri and Pierru (2016), Matar et al. (2017), Matar and Anwer (2017) and Matar and Shabaneh (2020).

Raising oil prices to the market level would clearly lead to oil's displacement by less costly options, based on fuel use in 2018. These less costly options include energy efficiency improvements, reverse osmosis plants and renewable technology. The adoption of such technologies results in a higher allocation of natural gas for power generation (Matar and Anwer 2017). The corresponding investments for the power system are shown in Figure 5.

Figure 4. Fuels used for power generation in the long run both under the status quo and with liberalized fuel prices.

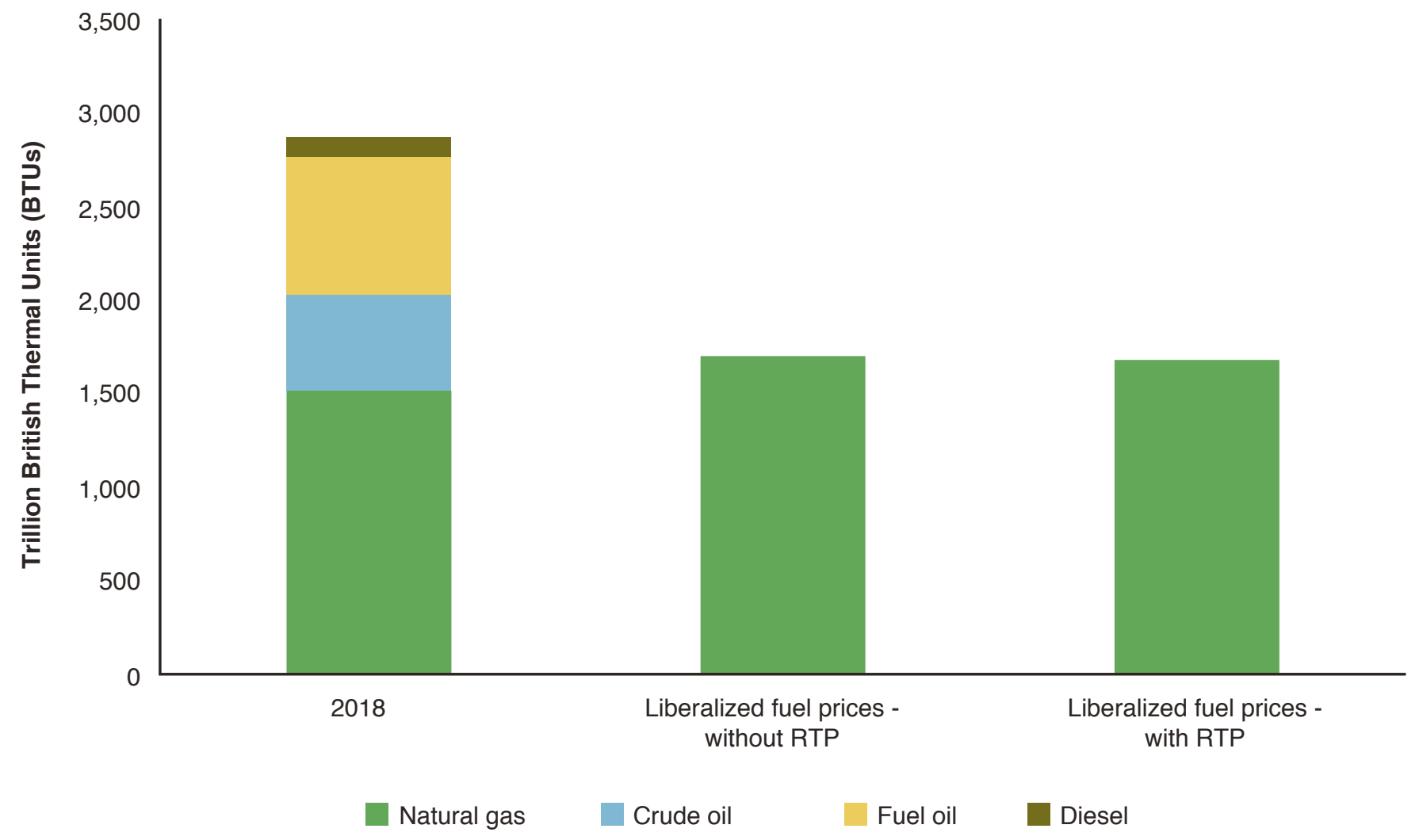

Sources: ECRA (2019) for 2018 data; model results for the liberalized fuel price cases. 
Figure 5. Long-run investment in new power plants when fuel prices are liberalized, with and without RTP.

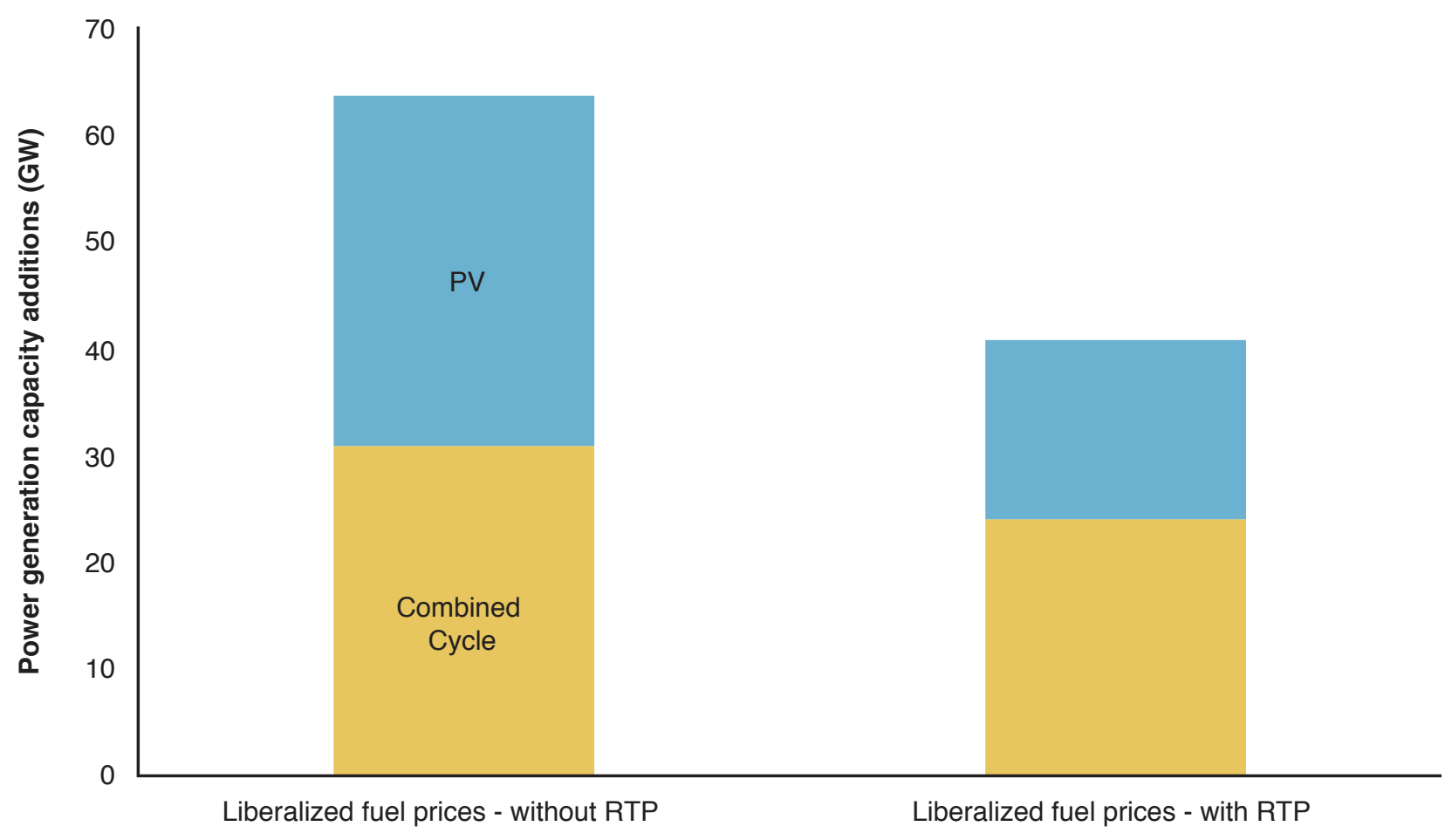

Source: model results.

With or without RTP, around 1,700 trillion British thermal units of natural gas are used in a liberalized fuel price environment. Although the use of natural gas is slightly lower when RTP is applied, it is similar in both liberalized fuel price scenarios. This is because the model uses natural gas first. Then, when the gas supply is exhausted, the next least-cost option is sought to meet the remaining power load demand. In this case, that option is renewable power technologies.

Although natural gas use is similar in both fuel price liberalization scenarios, the investment story begins to contrast the effects of RTP on power generation. Power plant capacity additions for fuel price liberalization with and without RTP are shown in Figure 5. Without RTP, the sector builds 33 gigawatts (GW) of solar PV plants and $31 \mathrm{GW}$ of natural gas-fired combined cycle plants. If RTP is implemented, however, PV capacity additions fall to $17 \mathrm{GW}$, around half of the total in the case of 2017 electricity prices. The combined cycle capacity falls to $24 \mathrm{GW}$ with RTP. In all, around \$24 billion in capital expenditures would be avoided with RTP. In the RTP case, the power load demand does not decrease to such a point that it can be satisfied with only natural gas. The demand response to RTP can help the power utility recoup the $\$ 2.4$ billion (9 billion $\mathrm{SAR}$ ) it has spent to overhaul residential electricity meters.

Figures 6 and 7 present the long-run marginal power production costs for Saudi Arabia's four regions. They show the costs in the summer and winter with and without RTP. Once it is deployed, PV energy is typically first in the merit order, as its marginal cost of generation is zero. Thus, in the cooler winter months, which have lower power loads than summer 
months in Saudi Arabia, marginal costs can fall to zero in the late morning and early afternoon. The
PV capacity deployed to meet summertime demand permits this outcome.

Figure 6. Long-run marginal costs of electricity delivery on a summer weekday after liberalizing fuel prices, with and without RTP.

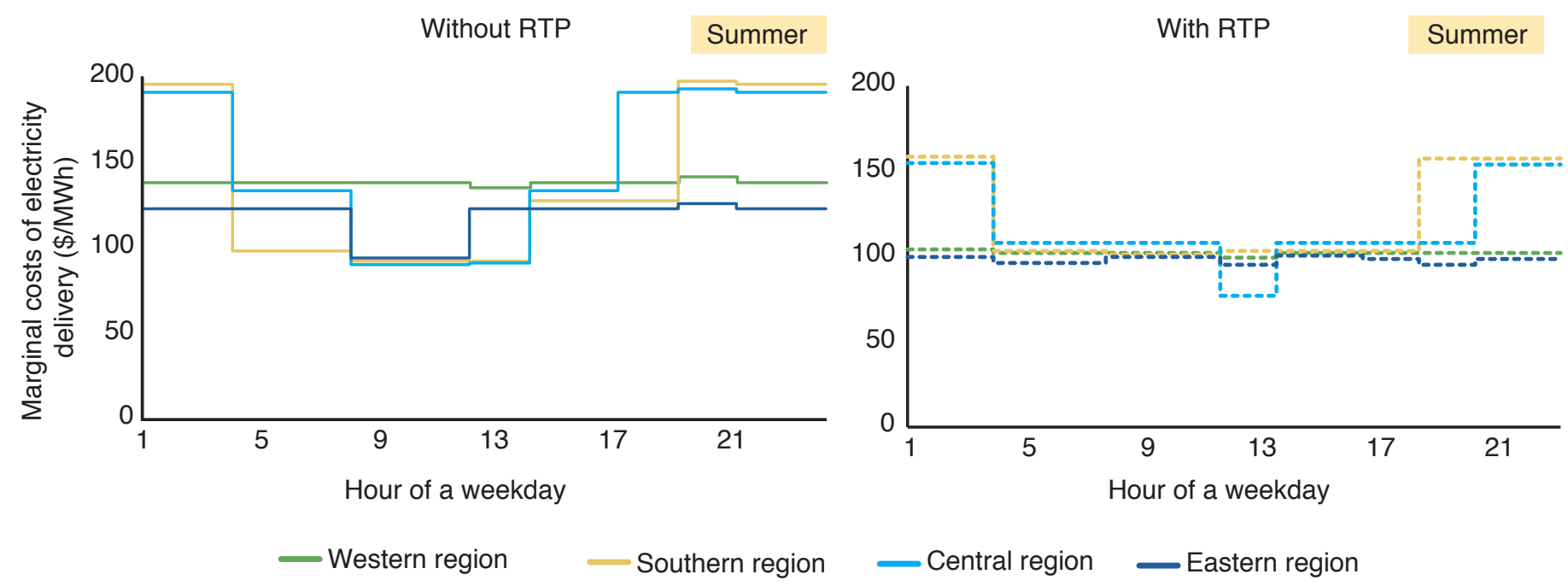

Source: model results.

Figure 7. Long-run marginal costs of electricity delivery on a winter weekday after liberalizing fuel prices, with and without RTP.

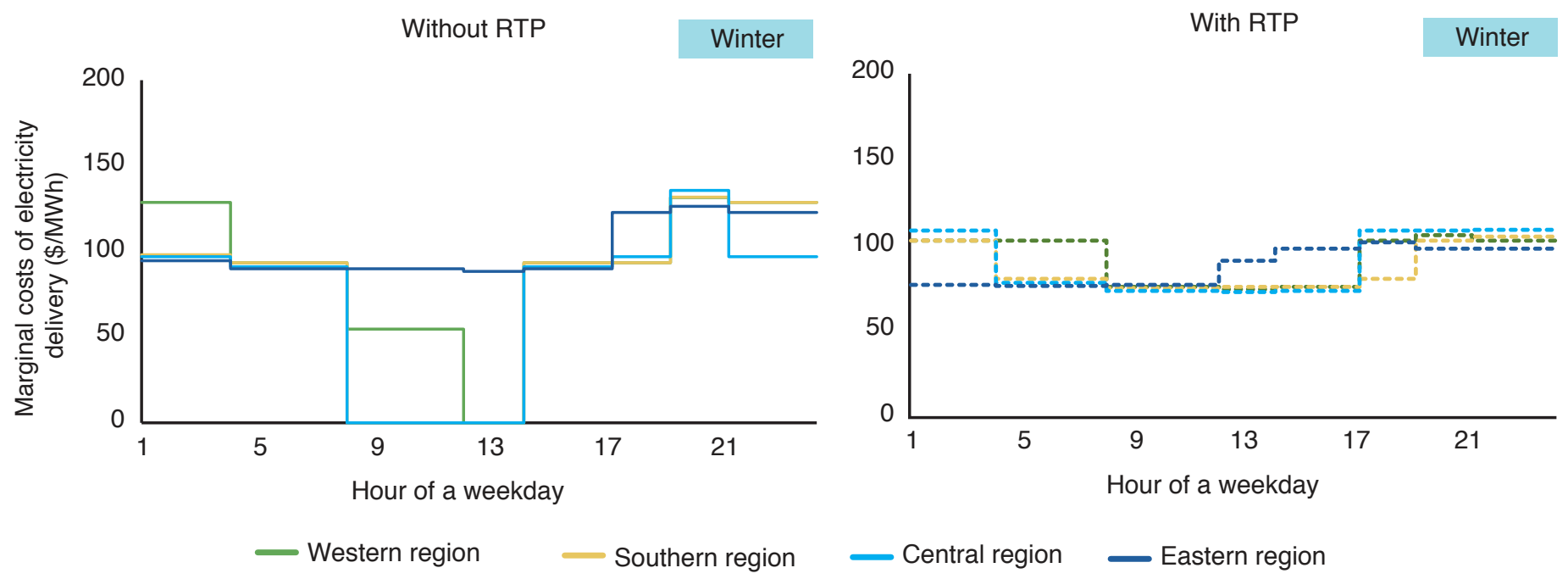

Source: model results. 
With RTP in place, households' power loads fall, which in turn lowers investments in PV capacity. In particular, the power loads fall during the peak period. The reduction in PV capacity results in a flatter 'duck curve' 6 in the summer. In other words, the power system experiences less ramping up and down of thermal power plants. Additionally, the trough in the summer daytime portion of the load curve is higher. The lower PV investment in the RTP scenario also reduces or eliminates the occurrence of zero prices in the winter.

In summary, the power system's marginal cost of supply does not rise as high or fall as low with RTP. Relative to the case with fuel price liberalization and no RTP, the consumer benefits from more stable electricity prices throughout the year. Thus, the key takeaways from this section are:

- In the long run, real-time electricity pricing reduces the variability of the marginal costs in the power generation sector.

- During the summer, RTP is the lowest during or around the system peak (ECRA 2020b). This outcome may result in unwanted load shifting to the peak load segment.

Although the power supply is this study's focus, the results reveal the underlying reasons for the lower electricity demand and the stabilized marginal costs when RTP is applied. The residential modeling framework shows that households make behavioral adjustments and invest in energy efficiency in the long run in response to RTP's higher electricity prices. These measures reduce dwellings' cooling loads and, thus, the power load reduction is greatest during the middle of the day.

The measures that are exercised in response to RTP in the model are not the actual measures that would be exercised in practice. The energy efficiency options are constrained in our model, and the analysis is performed for archetypical dwellings, whereas real households are heterogeneous. However, the results are indicative of households' responses. As in Matar (2020), households' responses in this model entail buying more efficient air conditioners and lighting and weatherizing their dwellings. Households' behavioral adjustments include raising their thermostat settings in the summer, spring and fall. Table 5 shows how lowand high-income households' responses to RTP differ in this model.

For example, in all regions but the west, low-income households in apartments react more drastically by setting their indoor temperatures higher than in the base case in the spring and fall. Their high-income counterparts, by contrast, do not adjust their thermostats in the spring and fall. This result arises in most regions because higher-income households have higher disposable incomes than lower-income households after electricity prices are raised. The responses described in Table 4 are all presented relative to the base case with 2017 electricity prices. In that case, households do not react behaviorally or make any higher energy efficiency purchases. 
Table 5. Response measures exercised by households under RTP.

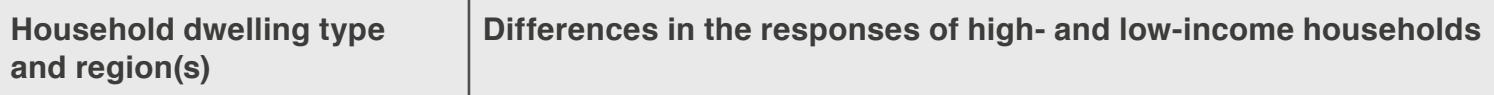

Both high- and low-income households purchase more efficient air conditioners, weatherize their homes and replace lightbulbs. Both household types also adjust their thermostats in the summer, spring, and fall and reduce lighting use. High-income households raise the thermostat set point during the summer peak more than low-income households do.

Apartments in the south

The energy efficiency purchases are the same as those for villas in the south. The behavioral responses of both groups are similar. The only exception is that low-income households raise the thermostat set point during the summer peak more than high-income households do.

\section{Apartments in the west}

The energy efficiency purchases are the same as for the above household types. Among the behavioral responses, low-income households raise the thermostat set point in the spring and fall, whereas high-income households do not.

\section{Traditional houses in the} south, central and east
Energy efficiency purchases are the same in both groups. Low-income households, unlike high-income ones, raise the thermostat set point in the spring and fall. In the south, high-income households also respond in the spring and fall but not as starkly as low-income households do.

Sources: model results. 


\section{Conclusion}

his study explored the potential effects of real-time electricity pricing on the power generation sector's operations in Saudi Arabia. This analysis provides insights into the potential effects of such an electricity pricing scheme in a liberalized fuel pricing environment. To this end, it presents linked multi-sector energy and residential electricity use models.

The residential model embeds households, whose decisions are governed by microeconomic principles, within a physical building energy model. Energy flows in these dwellings adhere to physical laws, such as the law of energy conservation. The analysis disaggregates households into low- and high-income households living in archetypical villas, apartments and traditional houses. Different regions within the country are considered separately to account for their particular socioeconomic and climate characteristics.

RTP is specified as the time-varying long-run marginal cost of supplying electricity in the liberalized fuel pricing environment. RTP is offered solely to households; the electricity prices charged to other consumer segments remain unchanged.
Even so, the use of RTP has pronounced effects on overall load demand.

This analysis provides two key takeaways. First, RTP reduces the intraday variability of the marginal costs to Saudi power utilities relative to the case without RTP. When fuel prices are liberalized, RTP is higher than 2017 electricity prices, and power loads decrease in turn. Lower power loads lead to reduced investments in power plants in the long run. This reduction includes lower solar PV capacity additions to the Saudi power system. Given the lack of energy storage, reduced PV capacity additions mitigate the wide variation in the daytime and nighttime marginal costs of production. Lower PV capacity also mitigates the thermal plants' ramping requirement.

Secondly, the curtailed investment in power plants in the RTP scenario more than covers the cost of residential smart meter replacements. Total investments over time are estimated to be about \$24 billion lower in the RTP scenario. By comparison, the actual cost of smart meter replacements for all residential customers is estimated to be $\$ 2.4$ billion. 


\section{Endnotes}

1 The term 'delivery' means generation, transmission and distribution.

${ }^{2}$ The cost of service comprises the costs of fuel; purchased electricity from independent producers; non-fuel operational expenses, including transmission and distribution; depreciation; and capital expenses.

${ }^{3}$ The physical component used in this analysis is detailed in Matar (2016).

${ }^{4} \mathrm{~A}$ lower discount rate is tested in the version of the model used by Matar (2020). When electricity prices rise, households with lower discount rates make more reserved behavioral adjustments. Instead, they have a higher propensity to purchase the maximum level of energy efficiency.

${ }^{5}$ The Saudi Arabian Monetary Authority is now called the Saudi Central Bank. However, it retains the acronym SAMA.

6 'Duck curve' is a term coined by the California Independent System Operator. It stems from the work of Denholm, Margolis and Milford (2008) and signifies the effects of PV capacity on the residual load curve throughout the day. 


\section{References}

Alberini, Anna, Silvia Banfi, and Celine Ramseier. 2013. "Energy Efficiency Investments in the Home: Swiss Homeowners and Expectations about Future Energy Prices." The Energy Journal 34:49-86. https://doi.org/10.5547/01956574.34.1.3

Allcott, Hunt. 2011. "Rethinking Real-time Electricity Pricing." Resource and Energy Economics 33:82042. https://doi.org/10.1016/j.reseneeco.2011.06.003

Argaam. 2019. "Saudi Electricity Awards SAR 9 Bln Smart Meter Project to Local, Chinese Firms." December 15. Accessed June 22, 2020. https:// www.argaam.com/en/article/articledetail/id/1335418.

Bruderer Enzler, Heidi, Andreas Diekmann, and Reto Meyer. 2014. "Subjective Discount Rates in the General Population and Their Predictive Power for Energy Saving Behavior." Energy Policy 65:524-40. https://doi.org/10.1016/j.enpol.2013.10.049

Denholm, Paul, Robert Margolis, and James Milford. 2008. "Production Cost Modeling for High Levels of Photovoltaics Penetration." Technical report NREL/ TP-581-42305. https://doi.org/10.2172/924642

Dewees, Donald N. 2001. Price and Environment in Electricity Restructuring. Law and Economics Programme, Faculty of Law, University of Toronto: 9.

Dutta, Goutam, and Krishnendranath Mitra. 2017. "A Literature Review on Dynamic Pricing of Electricity." Journal of the Operational Research Society 68:1131-45. https://doi.org/10.1057/ s41274-016-0149-4

Electricity \& Cogeneration Regulatory Authority (ECRA). 2016. "Electricity Tariff." Fourth Edition, April 2016.
- - . 2018. "Activities and Achievements of the Authority in 2017." 128, 153, 154. (Arabic release)

- - . 2019. "Annual Statistical Booklet For

Electricity \& Seawater Desalination Industries. 151.

- - . 2020a. "Activities and Achievements of the Authority in 2018." 66, 133. (Arabic release)

- - . 2020b. "Annual Statistical Booklet for Electricity and Seawater Desalination Industries 2019." 37.

Faruqui, Ahmad, Ryan Hledik, Greg Wikler, Debyani Ghosh, Joe Prijyanonda, and Nilesh Dayal. 2011. "Bringing Demand-side Management to the Kingdom of Saudi Arabia." The Brattle Group. 40. https://doi.org/10.1007/978-1-4615-0877-9_3

Faruqui, Ahmad, Ryan Hledik, and Jennifer Palmer. 2012. "Time-Varying and Dynamic Rate Design."

The Brattle Group: Global Power Best Practice Series. 17-8.

Faruqui, Ahmad, and Sanem Sergici. 2010. "Household Response to Dynamic Pricing of Electricity: A Survey of 15 Experiments." Journal of Regulatory Economics 38:193-225. https://doi. org/10.1007/s11149-010-9127-y

Faruqui, Ahmad, Sanem Sergici, and Lamine Akaba. 2013. "Dynamic Pricing of Electricity for Residential Customers: The Evidence from Michigan." Energy Efficiency 6:571-84. https://doi.org/10.1007/ s12053-013-9192-z

General Authority for Statistics (GaStat). 2018. Household Expenditure and Income Survey 2018. 2018:110. 
Harrison, Glenn W., Morten I. Lau, and Melonie B. Williams. 2002. "Estimating Individual Discount Rates in Denmark: A Field Experiment." American Economic Review 92(5):1606-17. https://doi. org/10.1257/000282802762024674

Hausman, Jerry A. 1979. "Individual Discount Rates and the Purchase and Utilization of Energy-Using Durables." Bell Journal of Economics 10(1):33-54. https://doi.org/10.2307/3003318

Herter, Karen, Vikki Wood, and Shelley Blozis. 2013. "The Effects of Combining Dynamic Pricing, AC Load Control, and Real-time Energy Feedback: SMUD'S 2011 Residential Summer Solutions Study." Energy Efficiency 6:641-53. https://doi.org/10.1007/ s12053-013-9209-7

Johansson, Per-Olov. 1991. An Introduction to Modern Welfare Economics. New York: Cambridge University Press. https://doi.org/10.1017/ cbo9780511582417

KAPSARC. 2016. "The KAPSARC Energy Model for Saudi Arabia: Documentation of the Model Build called 'KEM-SA_v9.16.'” Accessed January 16, 2020. https://www.kapsarc.org/wp-content/ uploads/2016/11/KEM-SA_documentation_v9.16.pdf.

Matar, Walid. 2016. "Beyond the End-consumer: How Would Improvements in Residential Energy Efficiency Affect the Power Sector in Saudi Arabia?" Energy Efficiency 9(3):771-90. https://doi. org/10.1007/s12053-015-9392-9

- - - 2017. "A Look at the Response of Households to Time-of-use Electricity Pricing in Saudi Arabia and its Impact on the Wider Economy." Energy Strategy Reviews 16:13-23. https://doi. org/10.1016/j.esr.2017.02.002
- - . 2018. "Households' Response to Changes in Electricity Pricing Schemes: Bridging Microeconomic and Engineering Principles." Energy Economics 75:300-08. https://doi.org/10.1016/j. eneco.2018.08.028

- - - 2019. "A Household's Power Load Response to a Change in the Electricity Pricing Scheme: An Expanded Microeconomic-Physical Approach." The Electricity Journal 32:106644. https://doi. org/10.1016/j.tej.2019.106644

- - - 2020. "Residential Energy Efficiency Investment and Behavioral Response under Different Electricity Pricing Schemes: A Physical-Microeconomic Approach." International Journal of Sustainable Energy. https://doi.org/10.108 0/14786451.2020.1785467

Matar, Walid, and Murad Anwer. 2017. "Jointly Reforming the Prices of Industrial Fuels and Residential Electricity in Saudi Arabia." Energy Policy 109:747-56. https://doi.org/10.1016/j. enpol.2017.07.060

Matar, Walid, Rodrigo Echeverri, and Axel Pierru. 2016. "The Prospects for Coal-fired Power Generation in Saudi Arabia." Energy Strategy Reviews 13-14:181-90. https://doi.org/10.1016/j. esr.2016.10.004

Matar, Walid, Frederic Murphy, Axel Pierru, and Bertrand Rioux. 2015. "Lowering Saudi Arabia's Fuel Consumption and Energy System Costs without Increasing End Consumer Prices." Energy Economics 49:558-69. https://doi.org/10.1016/j. eneco.2015.03.019 
Matar, Walid, Frederic Murphy, Axel Pierru, Bertrand Rioux, and David Wogan. 2017. "Efficient Industrial Energy Use: The First Step in Transitioning Saudi Arabia's Energy Mix." Energy Policy 105:80-92. https://doi.org/10.1016/j.enpol.2017.02.029

Matar, Walid, and Rami Shabaneh. 2020. "Viability of Seasonal Natural Gas Storage in the Saudi Energy System." Energy Strategy Reviews 32:100549. https://doi.org/10.1016/j.esr.2020.100549

Saudi Arabian Monetary Authority (SAMA). 2019. "Annual Statistics 2018."
Saudi Electricity Company (SEC). 2020. "Financial Results for the Fiscal Year Ended 31 December 2019." 2.

Saudi Vision 2030. 2017. "Fiscal Balance Program: Balanced Budget 2020." 38.

Yang, Changhui, Chen Meng, and Kaile Zhou. 2018. "Residential Electricity Pricing in China: The Context of Price-based Demand Response." Renewable and Sustainable Energy Reviews 81:2870-78. https://doi. org/10.1016/j.rser.2017.06.093 


\section{Appendix - Description of income classifications used in the analysis}

The distribution of income in a society is often measured using the Gini coefficient. The most recent regional Gini coefficient data for Saudi Arabia were published by GaStat in 2018. The data were collected as part of a survey that started in early 2017 and ended in early 2018. Figure A1 shows the cumulative regional distributions of the low- $\left(y_{1}\right)$ and high-income $\left(y_{2}\right)$ groups. The condition that the cumulative income share of the second group must be greater than or equal to that of the first group is also stipulated. These two equations or inequalities are used to solve a system of two equations and two unknowns for each region. Equation A1 represents a discrete formulation of the Gini coefficient that resembles a Lorenz curve.

Table A.1. Income distribution among households.

Gini $=3-\frac{4 y_{1}+2 y_{2}}{y_{1}+y_{2}}$

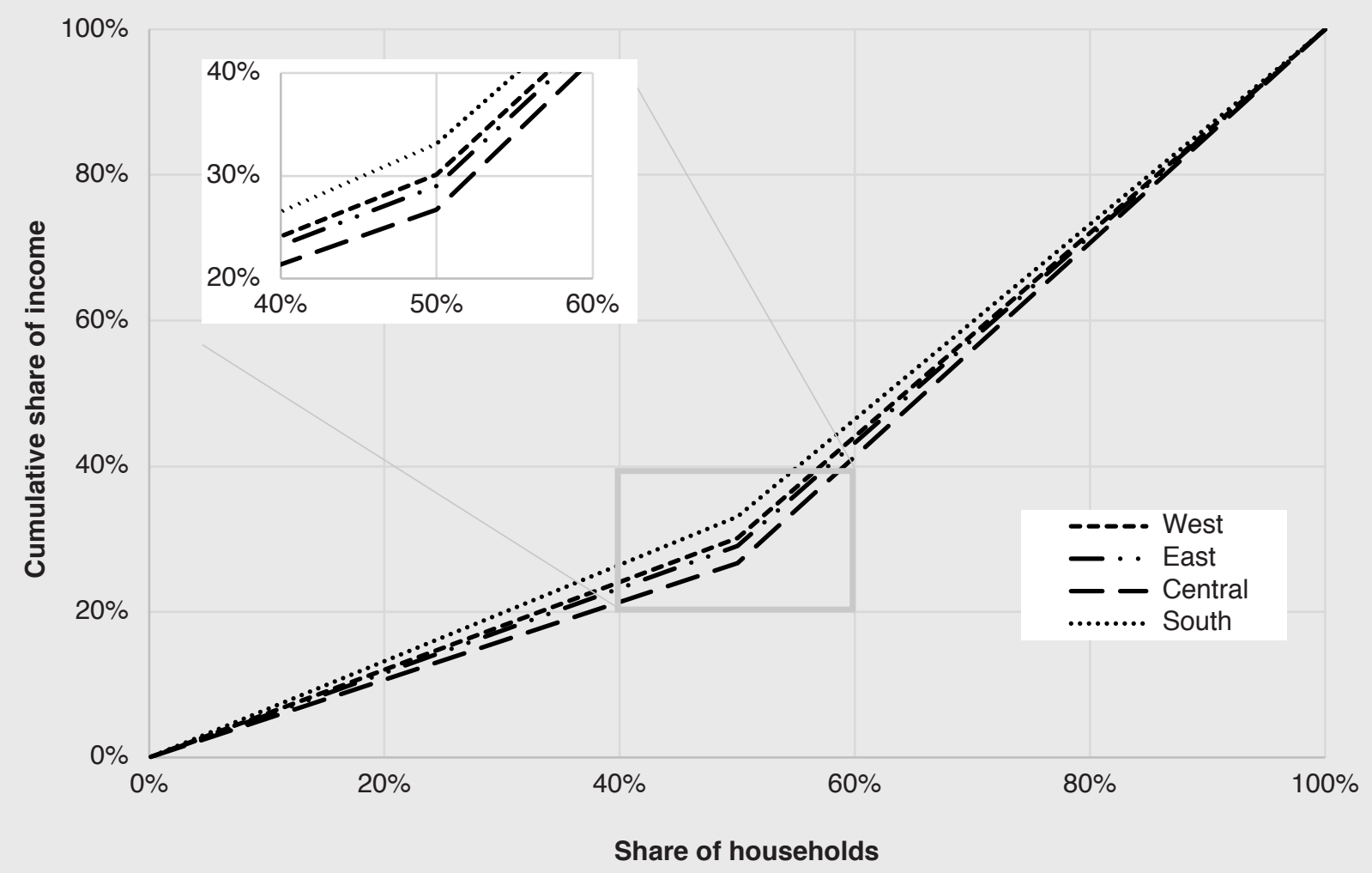

Sources: GAStat (2018); KAPSARC analysis. 
The cut-off point between the low- and high-incomes groups is $50 \%$. This analysis estimates the average monthly incomes in the areas above and below this cut-off point, shown in Table A1.

Table A1. Average monthly income level for each group by region.

\begin{tabular}{c|c|c} 
Region of Saudi Arabia & Low income (U.S. dollars) & High income (U.S. dollars) \\
\hline Central & 6,525 & 17,914 \\
\hline Western & 6,646 & 15,434 \\
\hline Southern & 7,266 & 14,685 \\
\hline Eastern & 8,340 & 20,419
\end{tabular}

Source: KAPSARC analysis. 


\section{Notes}


Notes

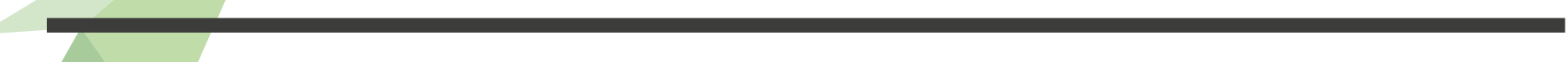




\section{Notes}

- 


\section{About the Author}

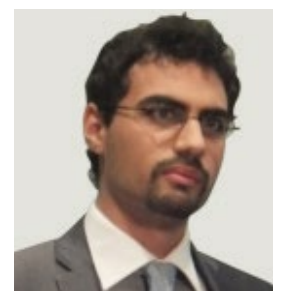

\section{Walid Matar}

Walid is a research fellow at KAPSARC who works on energy systems models, including the KAPSARC Energy Model, and satellite projects, such as KAPSARC's residential electricity use model. Walid holds a Master of Science degree in mechanical engineering from North Carolina State University and a Bachelor of Science degree in the same field from the University of South Carolina.

\section{About the Project}

This project aims to develop a framework for analyzing households' price responses to any electricity pricing scheme, especially in regions with unavailable or insufficient statistical data. The framework combines physical and microeconomic principles. The physical component of the framework governs electricity use throughout the day. The microeconomic component imposes a normative utility function on households to represent their satisfaction. 
INAPSARC

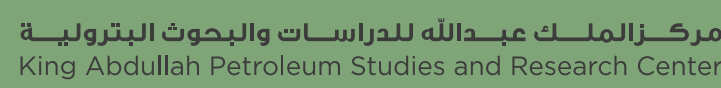

www.kapsarc.org 